\title{
Ga Dopant Induced Band Gap Broadening and Conductivity Enhancement in Spray Pyrolysed $\mathrm{Zn}_{0.85} \mathrm{Ca}_{0.15} \mathrm{O}$ thin Films
}

\author{
Nripasree Narayanan ${ }^{a}$, Deepak $N^{a} *$ (D) \\ ${ }^{a}$ Department of Physics, Kannur University, Payyanur Campus, Kerala, India 670327
}

Received: January 12, 2018; Revised: June 08, 2018; Accepted: August 06, 2018

\begin{abstract}
Ga doped $\mathrm{Zn}_{0.85} \mathrm{Ca}_{0.15} \mathrm{O}$ thin films were prepared by spray pyrolysis method and studied the impact of Ga doping concentration on the physical properties of these films. XRD analysis confirmed the structural purity and polycrystalline nature of the films and composition analysis verified the incorporation of dopants in the structures. Optical transmission in the visible range initially increased and at higher Ga concentration decreased in accordance with the crystalline quality. Energy gap increased with doping percentage due to Burstein-Moss effect arising from the increase in carrier concentration. Ga doping resulted in enhanced electron concentration and consequently obtained lower resistive $\mathrm{n}$ type thin films. At higher doping level, electron density decreased due to the limit of solid solubility and hence conductivity slightly decreased but energy gap increased due to the extended localization arising from the poor crystallinity. Mobility decreased with doping due to the increased ionized impurity scattering at lower dopant concentration and due to intra-grain cluster scattering at heavy doping.
\end{abstract}

Keywords: $Z n_{0.85} C a_{0.15} O$, Ga doping, spray pyrolysis, Burstein-Moss effect.

\section{Introduction}

Transparent and conducting oxides (TCOs) are an unparalleled class of materials which have been undergoing serious research for the last few decades. TCOs found immense applications in electronics and optoelectronics such as flat panel displays, light emitting diodes (LEDs), window defrosters, thin film solar cells, surface acoustic wave (SAW) devices, thin film transistors, etc. ${ }^{1-6}$ In the beginning, indium oxide $\left(\operatorname{In}_{2} \mathrm{O}_{3}\right)$ had been widely used in various TCO applications. But later on it was discarded due to its scarcity and replaced by the low cost, abundant, less toxic and biocompatible zinc oxide $(\mathrm{ZnO})$. $\mathrm{ZnO}$ is a wide band gap semiconducting material $(\sim 3.37 \mathrm{eV})$. It exhibits better piezoelectric properties and possesses large free exciton binding energy $(\sim 60 \mathrm{meV})$ at room temperature.

The interest of materials researchers on $\mathrm{ZnO}$ is fuelled and fanned by the viability of tunable electrical properties and tailorable optical energy gap. The electrical conductivity of $\mathrm{ZnO}$ can be fine tuned and enhanced by adding group III elements such as B, Al, Ga and In. The optical energy gap can be engineered by forming alloys with other oxide materials with different optical energy gap. Thus $\mathrm{ZnO}$ can be alloyed with a variety of elements to tailor the band gap. For example, by alloying with a wider band gap material like $\mathrm{MgO}(\mathrm{Eg}=7.8 \mathrm{eV})$, we will get an alloy of $\mathrm{Zn}_{(1-\mathrm{x})} \mathrm{Mg}_{\mathrm{x}} \mathrm{O}$ with larger optical energy gap ${ }^{7}$. Similarly, in order to decrease the band gap, cadmium can be mixed to $\mathrm{ZnO}^{8}$. Also we can extend this method with other earth alkaline elements like Be and $\mathrm{Ca}$ and these will find applications in optoelectronic devices. However, there have been very few reports on the properties

*e-mail: dr.deepaknk@yahoo.com of $\mathrm{Zn}_{(1-x)} \mathrm{Ca}_{\mathrm{x}} \mathrm{O}$ thin films ${ }^{9}$. Deposition and characterization of thin films of undoped and doped $\mathrm{ZnO}$ have been extensively investigated and huge number of reports is already available in the literature. Researchers opted various deposition strategies and succeeded in achieving good quality $\mathrm{ZnO}$ thin films on a variety of substrates. In this work, thin films of gallium (Ga) doped $\mathrm{Zn}_{0.85} \mathrm{Ca}_{0.15} \mathrm{O}$ were deposited on glass substrates by spray pyrolysis method and studied the influence of $\mathrm{Ga}$ doping concentration on the various physical properties. The particular stoichiometric composition of $\mathrm{Zn}_{0.85} \mathrm{Ca}_{0.15} \mathrm{O}$ was preferred for the present study because thin film of this composition resulted in promising physical properties as concluded in our earlier study ${ }^{10}$. Spray pyrolysis was adopted for the deposition of thin films as it is simple and non-vacuum technique for film deposition over large area and doping can be easily accomplished by adding the salts of the desired dopants into the precursor solution during its preparation.

\section{Materials and Methods}

$\mathrm{Zn}_{0.85} \mathrm{Ca}_{0.15} \mathrm{O}$ thin films doped with 1 - 4 at $\%$ Ga were deposited on hot glass substrates kept at a temperature of $400 \pm 10^{\circ} \mathrm{C}$ by spray pyrolysis technique (Holmarc HOTH-04). Prior to film deposition, glass substrates were cleaned with diluted chromic acid, sodium hydroxide solution and acetone followed by ultrasonic bath cleaning in hot distilled water. $15 \% \mathrm{Ca}^{2+}$ substituted $\mathrm{ZnO}$ thin films were prepared with $0.4 \mathrm{M}$ aqueous solutions of zinc acetate dihydrate $\left[\mathrm{Zn}\left(\mathrm{CH}_{3} \mathrm{COO}\right)_{2} .2 \mathrm{H}_{2} \mathrm{O}\right]$ and calcium acetate monohydrate $\left[\mathrm{Ca}\left(\mathrm{CH}_{3} \mathrm{COO}\right)_{2}\right.$. $\left.\mathrm{H}_{2} \mathrm{O}\right]$. Compressed air was used for atomizing the precursor solution and the solution flow rate was $2 \mathrm{ml} /$ min. Details of the deposition system and conditions were 
reported elsewhere ${ }^{10}$. Ga doping with different concentrations was achieved by adding equivalent quantities of gallium nitrate $\left(\mathrm{GaNO}_{3}\right)$ in the precursor of $\mathrm{Zn}_{0.85} \mathrm{Ca}_{0.15} \mathrm{O}$.

Structural mapping of the as-deposited films were done with Rigaku Miniflex 600 X-ray Diffractometer operating at a voltage of $40 \mathrm{kV}$ using $\mathrm{Cu}-\mathrm{K} \alpha(1=1.5406 \AA)$ radiation. Surface morphology and chemical composition of the films were investigated with JEOL Model JSM 6390 scanning electron microscope attached with JEOL Model JED 2300. Optical characterization of the films was carried out with JASCO V-650 double beam spectrophotometer. The optical energy gap was derived from the transmittance spectra. Electrical properties such as carrier type, concentration (n), mobility $(\mu)$ and resistivity $(\rho)$ of the films were measured using Ecopia Hall Effect Measurement System (HMS 3000 VER 3.52). For the measurement, a magnetic field of strength $0.55 \mathrm{~T}$ was applied to the films configured in Van der Pauw geometry. Highly conducting silver paste was used to make ohmic contacts at the four corners in the Van der Pauw configuration. These contacts were then properly heated and allowed to dry to carry out electrical characterization.

\section{Results and Discussions}

\subsection{Structural properties}

Structural analysis of the as-deposited thin films was carried out with the X-ray diffraction (XRD) spectra shown in Figure 1. XRD pattern revealed the polycrystalline character of the films and conformed to hexagonal wurtzite structure without showing any trace of impurity phases such as $\mathrm{Ga}_{2} \mathrm{O}_{3}$, $\mathrm{CaO}$ etc. owing to the incorporation of both dopants in the ZnO lattice (JCPDS 36-1451). All films, except the 4 at $\%$ Ga doped one, assumed the preferential orientation along the (002) plane, c-axis normal to the substrate surface. 1 and 2

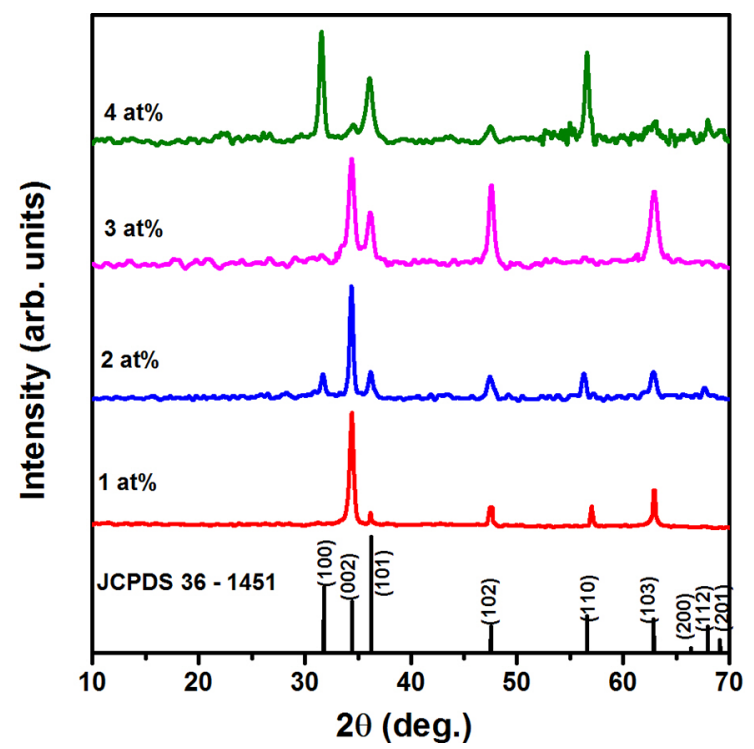

Figure 1. XRD patterns of differently Ga doped $\mathrm{Zn}_{0.85} \mathrm{Ca}_{0.15} \mathrm{O}$ thin films. at $\%$ Ga doping resulted in highly textured growth along the (002) plane having minimum surface energy while 3 at $\%$ doping favoured growth of grains along other directions also. 4 at \% doped film is highly polycrystalline and showed a preferred growth along (100) plane. An estimation of the average (mean) crystallite size (D) has been done using the well-known formula of Scherrer ${ }^{11}$

$$
D=\frac{0.9 \lambda}{\beta \cos \theta}
$$

where $\beta$ is the observed angular width at half maximum intensity (FWHM) of each diffraction peak located at a peak position $2 \theta$ and $\lambda$ is the X-ray wavelength (1.5406 $\AA$ ). Table 1 summarizes the results of calculation. The average crystallite size initially increased with Ga doping due to the highly textured growth while for 3 and 4 at \% doped films, crystallinity deteriorated. Excess dopants cause perturbation in the lattice periodicity by forming defects or disorders and thereby densify grain boundaries. Moreover, impurity doping induces stress in the structure which also deteriorates the crystalline quality of the films ${ }^{12}$.

\subsection{Morphology and compositional analysis}

Scanning electron microscope (SEM) images of the asdeposited thin films were shown in Figure 2. All the films exhibited nanostructured grains and showed no void spaces and confirmed the uniform growth of grains over the substrate surfaces. The EDX spectra shown in Figure 3 confirmed the presence of $\mathrm{Ca}$ and $\mathrm{Ga}$ in the $\mathrm{ZnO}$ lattice.

\subsection{Optical properties}

Optical properties of the deposited thin films were studied using the transmittance spectra (Figure 4) measured in the 300-900 nm spectral region. The films possessed better optical transmission in the visible and near infrared region. 1and 2 at $\%$ doping slightly enhanced the average transmittance but showed degradation at higher doping concentration due to the deterioration in crystallinity. The increased free carrier absorption and scattering of photons by the crystal defects were responsible for the poor transmittance. The oscillatory character of the transmission spectra arising from the interference showed that the films' surfaces are smoother. The fundamental absorption edge corresponding to the interband electronic transitions had undergone a blue-shift with Ga doping suggesting band gap broadening. The absorption coefficient $(\alpha)$ varies with the incident photon energy (hv) and obeys the Tauc relation ${ }^{13}$

$$
\alpha=\frac{B}{h v}\left(h v-E_{g}\right)^{n}
$$

where $\mathrm{B}$ and $\mathrm{n}$ are constants independent of the photon energy and $\mathrm{n}$ is equal to $1 / 2$ as $\mathrm{ZnO}$ is a direct band gap material. The plots of $(\alpha h v)^{2}$ versus (hv) for the films were shown in Figure 5. Energy gap values were calculated and presented 
Table 1. Average crystallite size (D), energy gap (Eg) and experimental and theoretical values of Burstein-Moss shift $\left(\Delta \mathrm{E}_{\mathrm{BM}}\right)$ of $\mathrm{Zn}_{0.85} \mathrm{Ca}_{0.15} \mathrm{O}$ and $\mathrm{Ga}$ doped $\mathrm{Zn}_{0.85} \mathrm{Ca}_{0.15} \mathrm{O}$ thin films.

\begin{tabular}{lccccc}
\hline \multirow{2}{*}{$\begin{array}{l}\text { Ga Concentration } \\
\text { (at \%) }\end{array}$} & $\mathrm{D}(\mathrm{nm})$ & $\mathrm{E}_{\mathrm{g}}(\mathrm{eV})$ & \multicolumn{2}{c}{$\Delta \mathrm{E}_{\mathrm{BM}}(\mathrm{eV})$} & Reference \\
\hline 0 & 13.16 & 3.505 & Experimental & Theoretical & \\
1 & 21.23 & 3.548 & 0.043 & - & 10 \\
2 & 20.47 & 3.552 & 0.047 & 0.111 & Present study \\
3 & 10.25 & 3.556 & 0.051 & 0.154 & Present study \\
4 & 8.34 & 3.589 & 0.084 & 0.064 & Present study \\
\hline
\end{tabular}
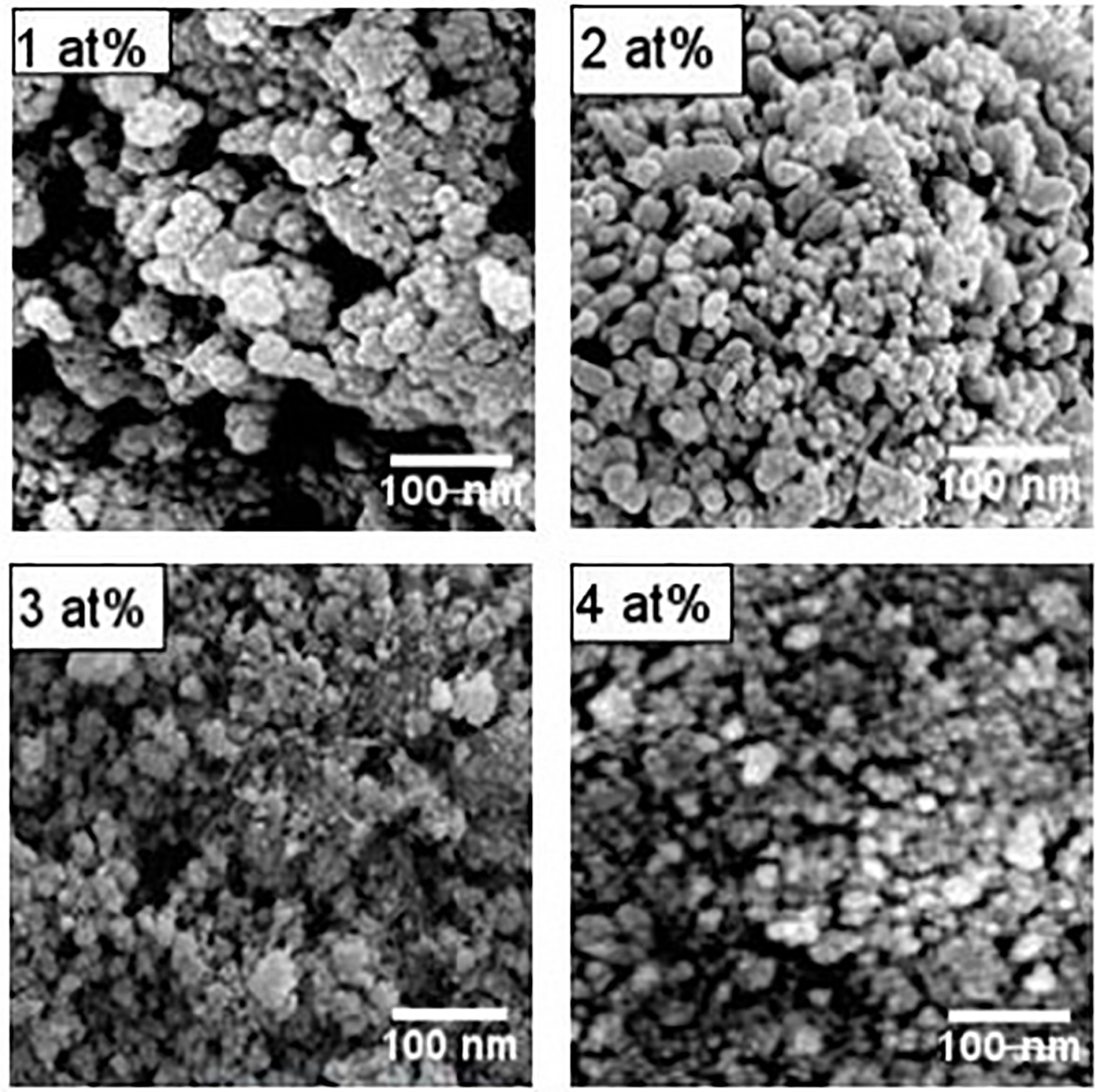

Figure 2. SEM images of $\mathrm{Ga}$ doped $\mathrm{Zn}_{0.85} \mathrm{Ca}_{0.15} \mathrm{O}$ thin films.

in Table 1. Band gap energy increased with Ga doping concentration due to the increase in carrier concentration known as Burstein-Moss (BM) effect. In heavily doped semiconductors, excess electrons occupy levels near the conduction band minimum. As optical transitions are vertical in $\mathrm{ZnO}$ and Pauli Exclusion Principle restricts states to be singly occupied, valence electrons need additional energy to excite to the higher states in the conduction band. According to Burstein, the magnitude of Burstein-Moss shift $\left(\Delta \mathrm{E}_{\mathrm{BM}}\right)$ in energy gap defined as the shift of Fermi level with respect 
1 at $\% \mathrm{Ga}$

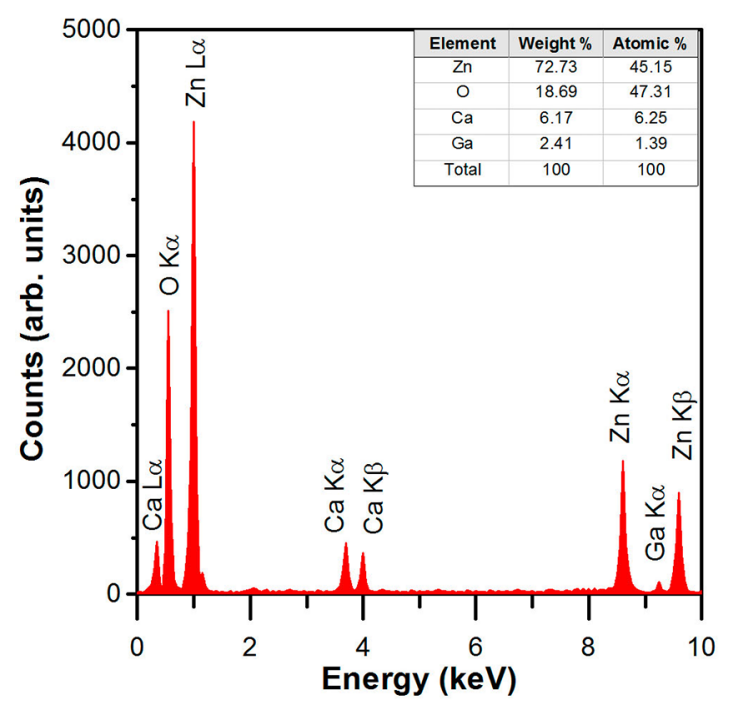

3 at $\% \mathrm{Ga}$

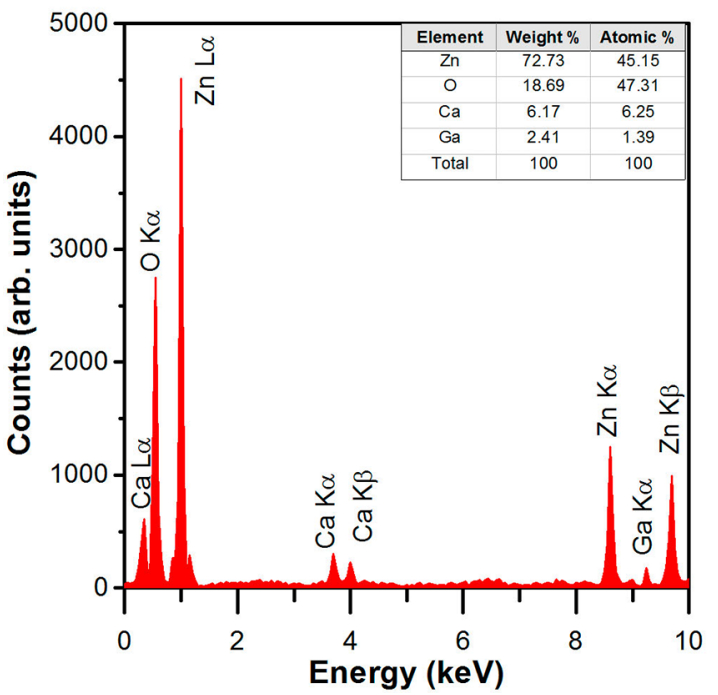

Figure 3. EDX spectra of Ga doped $\mathrm{Zn}_{0.85} \mathrm{Ca}_{0.15} \mathrm{O}$ thin films.

to the bottom of the conduction band can be approximated using the relation ${ }^{14}$

$$
\Delta E_{B M}=\frac{2}{2 m^{*}}\left(3 \pi^{2} n\right)^{2 / 3}
$$

where $h$ is the Plancks constant, $\mathrm{m}$ * is the electron effective mass, and $\mathrm{n}$ is the electron density determined from Hall effect measurements. We use $\mathrm{m}^{*}=0.26 \mathrm{~m}_{0}$ assuming that the bottom of the conduction band is located at the centre of the Brillouin zone and therefore the electron effective mass remains unchanged within the occupied part of the conduction band ${ }^{15,16}$. The calculated values along with the experimentally measured shifts were summarized in Table 1. It was obvious from the table that theoretically determined values of BM shift (using equation (3)) were larger than

\section{2 at $\% \mathrm{Ga}$}

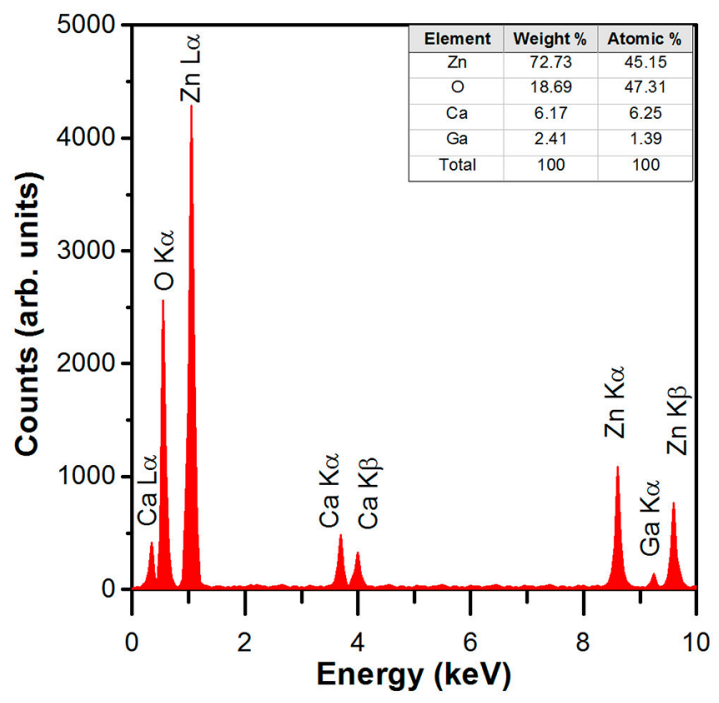

4 at $\% \mathrm{Ga}$

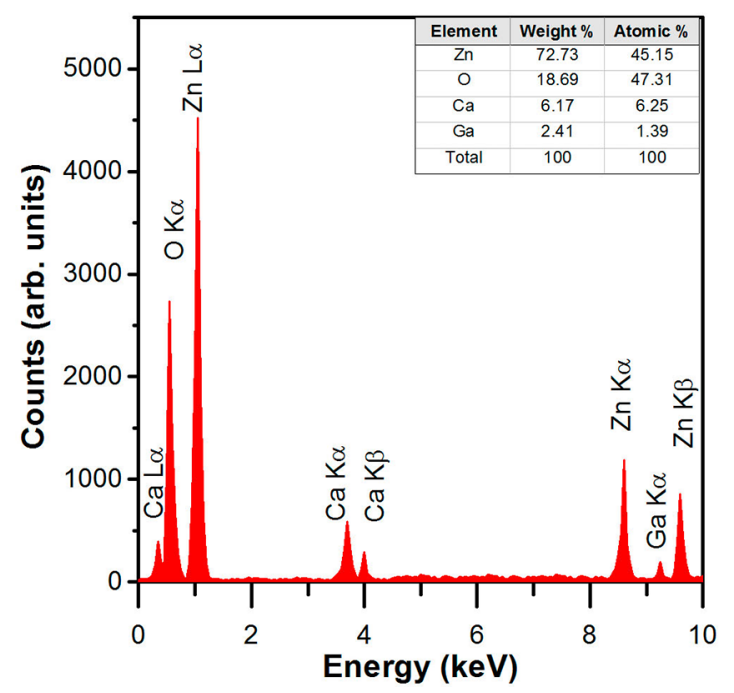

the experimental shift. This discrepancy can be explained on the basis of the combined effects of non-parabolicity of the conduction band in heavily doped semiconductors and the phenomenon of band gap narrowing (BGN) ${ }^{17,18}$. In heavily doped degenerate semiconductors, effective mass of electrons varies with carrier concentration because of the non-parabolicity of the conduction band and consequently the equation for effective mass needs some correction as suggested by $\mathrm{Lu}$ et $\mathrm{al}^{17}$. BGN is the result of band gap renormalization arising from many-body effects of free carriers in the valence and conduction bands. In the case of $\mathrm{n}$ type semiconductors, these many body effects include electron-electron interactions, electron-hole interactions and electron-donor interactions. From the details of Hall measurement, the carrier concentration decreased for 4 


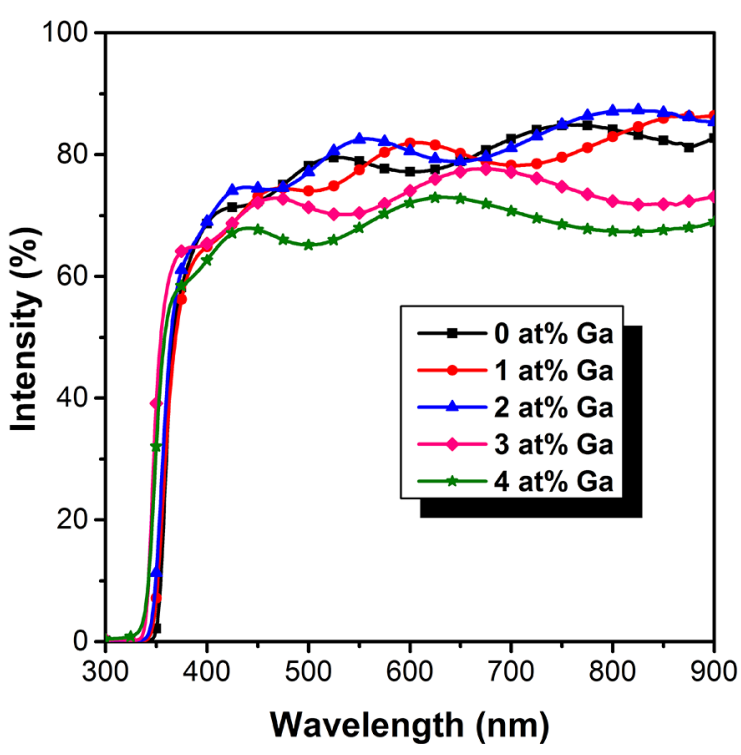

Figure 4. Transmittance spectra of $\mathrm{Ga}$ doped $\mathrm{Zn}_{0.85} \mathrm{Ca}_{0.15} \mathrm{O}$ thin films.

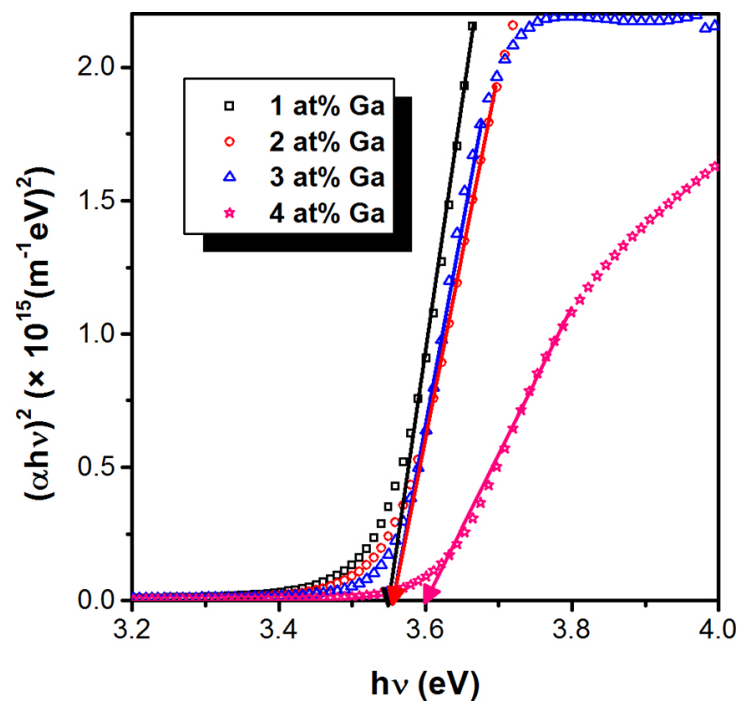

Figure 5. Tauc plot of $\mathrm{Ga}$ doped $\mathrm{Zn}_{0.85} \mathrm{Ca}_{0.15} \mathrm{O}$ thin films for band gap energy $\left(\mathrm{E}_{\mathrm{g}}\right)$ determination.

at $\%$ doping, but energy gap still increased. This could be in part related to the degraded crystallinity which increases the localization near the valence and conduction bands and hence broadens the optical energy gap.

\subsection{Electrical properties}

Carrier type, concentration (n), mobility $(\mu)$ and resistivity ( $\rho$ ) of the samples obtained from the Hall measurement are listed in Table 2. All the films exhibited $n$ type electrical conductivity and Ga doping provided lower resistivity of the order of $10^{-2} \Omega \mathrm{cm}$. The carrier concentration enhanced with $\mathrm{Ga}$ doping except at higher doping levels while mobility decreased monotonously. The enhancement of electron density with doping is due to the substitution of $\mathrm{Ga}^{3+}$ in
Table 2. Carrier type, concentration $(\mathrm{n})$, mobility $(\mu)$ and resistivity ( $\rho$ ) of the $\mathrm{Zn}_{0.85} \mathrm{Ca}_{0.15} \mathrm{O}$ and $\mathrm{Ga}$ doped $\mathrm{Zn}_{0.85} \mathrm{Ca}_{0.15} \mathrm{O}$ thin films obtained from Hall effect measurement.

\begin{tabular}{lcccc}
\hline $\begin{array}{l}\text { Ga Concentration } \\
\text { (at \%) }\end{array}$ & Type & $\mathrm{n}\left(\mathrm{cm}^{-3}\right)$ & $\begin{array}{c}\mu\left(\mathrm{cm}^{2} /\right. \\
\mathrm{Vs})\end{array}$ & $\rho(\Omega \mathrm{cm})$ \\
\hline 0 & $\mathrm{n}$ & $7.34 \times 10^{16}$ & 6.38 & $1.33 \times 10^{1}$ \\
1 & $\mathrm{n}$ & $2.25 \times 10^{19}$ & 3.78 & $7.54 \times 10^{-2}$ \\
2 & $\mathrm{n}$ & $3.04 \times 10^{19}$ & 3.74 & $5.86 \times 10^{-2}$ \\
3 & $\mathrm{n}$ & $3.65 \times 10^{19}$ & 3.52 & $4.86 \times 10^{-2}$ \\
4 & $\mathrm{n}$ & $9.79 \times 10^{18}$ & $9.37 \times 10^{-1}$ & $7.69 \times 10^{-1}$ \\
\hline
\end{tabular}

$\mathrm{Zn}^{2+}$ lattice sites. Each of the substituted donor provides one excess electron and hence the conductivity improves. Many authors reported such an enhancement of carrier concentration by the substitution of gallium dopants in zinc sites and consequent reduction in resistivity in $\mathrm{ZnO}$ thin films ${ }^{19-21}$. However, after an optimum level of doping, due to the limit of solid solubility, dopants cannot occupy $\mathrm{Zn}$ sites and occupy some interstitial sites forming some sort of neutral defects and act as carrier traps thereby reducing carrier density and mobility. Hall measurement details manifest that carrier mobility decreased with increase in $\mathrm{Ga}$ dopant concentration which adversely affects the electrical conductivity even when the carrier concentration increases. The observed decrease in mobility is attributed to various scattering mechanisms such as ionized impurity scattering, neutral impurity scattering, grain boundary scattering, lattice vibration scattering and intra-grain cluster scattering. As neutral impurity concentration is much smaller than the electron density (same as the ionized impurity density) in the doped films, neutral impurity scattering cannot significantly affect electron mobility.Intentionally or unintentionally doped impurities generate long range Coulomb potentials which affect the motion of free carriers in the film. As the contribution of ionized impurity scattering to mobility ${ }^{22}$

$$
\mu_{i}\left(\frac{2}{m^{*}}\right)^{1 / 2} \frac{\varepsilon^{1 / 2} E_{F}^{1 / 3}}{\pi e^{3} N_{i} Z^{2}} \frac{1}{\ln \left(1+\frac{e E_{F}}{N_{i}^{1 / 3} Z e^{2}}\right)}
$$

is negatively correlated with the carrier concentration $(\mathrm{Ni}$ $=\mathrm{n}$ ), the observed decrease in mobility at low level doping can be explained as a consequence of ionized impurity scattering. The grain boundary scattering dependent mobility is ${ }^{23,24}$

$$
\mu_{g}=\mu_{0} T^{-1 / 2} \exp \left(-\frac{\Delta E}{k_{B} T}\right)
$$

This contribution becomes effective only when the mean free path of electrons becomes comparable with the crystallite size. Mean free path of electrons in semiconductors ${ }^{25}$

$$
L=\left(\frac{h}{2 e}\right)\left(\frac{3 n e}{\pi}\right)^{1 / 3} \mu_{H}
$$


is much smaller than the average crystallite size and hence its contribution can be ruled out. The lattice vibration scattering dependent mobility ${ }^{22}$

$$
\mu=\left(\frac{\pi}{3}\right)^{1 / 3} \frac{e h^{3} C_{1}}{\left(m^{*}\right)^{2} E_{d}^{2} k_{B} T n^{1 / 3}}
$$

becomes effective only at higher temperatures. Thus the main scattering centres which make contribution to mobility are ionized impurities. Further, it was observed that heavy doping resulted in decrease in carrier concentration as well as in mobility. This decrease in mobility can be attributed to the intra-grain cluster scattering accompanied with heavy doping. Similar change in scattering mechanisms from ionized impurity scattering (inter-grain) to intra-grain cluster scattering was observed by Das et al when $\mathrm{ZnO}$ thin films doped with $\mathrm{Al}^{26}$.

\section{Conclusions}

$\mathrm{Zn}_{0.85} \mathrm{Ca}_{0.15} \mathrm{O}$ thin films doped with $\mathrm{Ga}$ at different concentrations were deposited on glass substrates by spray pyrolysis technique. All the samples were nanostructured and polycrystalline and assumed hexagonal wurtzite geometry. Low level Ga doping improved the crystallinity due to the textured growth but further increase in doping concentration deteriorated crystallinity due to the defects and disorders introduced by the impurities. Optical transmittance also varied in accordance with the crystalline quality. The EDX spectra confirmed the presence of incorporated dopants. With donor doping, the band gap energy enhanced due to Burstein-Moss effect. Carrier concentration and electrical conductivity enhanced with Ga doping while mobility decreased due to ionized impurity scattering at lower dopant concentration and due to intra-grain cluster scattering at heavy doping. After an optimum level of doping, carrier concentration decreased and hence the film became more resistive. In summary Ga doping in $\mathrm{Zn}_{0.85} \mathrm{Ca}_{0.15} \mathrm{O}$ thin films resulted in band gap broadened and highly conductive thin film which will suit for various blue and ultraviolet applications.

\section{Acknowledgements}

First author would like to gratefully acknowledge the University Grants Commission (UGC), New Delhi for providing senior research fellowship (SRF).

\section{References}

1. Hartnagel HL, ed; Dawar AL, Jain AK, Jagadish C. Semiconducting Transparent Thin Films. Bristol: Institute of Physics Publishing; 1983.

2. Ginley DS, Bright C. Transparent Conducting Oxides. MRS Bulletin. 2000;25(8):15-18.
3. Granqvist CG. Transparent conductors as solar energy materials: A panoramic review. Solar Energy Materials and Solar Cells. 2007;91(17):1529-1598.

4. Fortunato E, Ginley D, Hosono H, Paine DC. Transparent Conducting Oxides for Photovoltaics. MRS Bulletin. 2007;32(3):242-247.

5. Hamberg I, Granqvist CG. Evaporated Sn-doped In2O3 films: Basic optical properties and applications to energy-efficient windows. Journal of Applied Physics. 1986;60(11)R123.

6. Batzill M, Diebold U. The surface and materials science of tin oxide. Progress in Surface Science. 2005;79(2-4):47-154.

7. Makino T, Segawa Y, Kawasaki M, Ohtomo A, Shiroki R, Tamura K, et al. Band gap engineering based on MgxZn1-xO and CdyZn1-yO ternary alloy films. Applied Physics Letters. 2001;78(9):1237-1239.

8. Ramakrishna Reddy KT, Prathap P, Revathi N, Reddy ASN, Miles RW. Mg-composition induced effects on the physical behavior of sprayed Zn1-xMgxO films. Thin Solid Films. 2009;518(4):1275-1278.

9. Misra KP, Shukla RK, Srivastava A, Srivastava A. Blueshift in optical band gap in nanocrystalline $\mathrm{Zn} 1$-xCaxO films deposited by sol-gel Method. Applied Physics Letters. 2009;95(3):031901.

10. Narayanan N, Deepak NK. Band gap bowing of nanocrystalline $\mathrm{Zn}(1-\mathrm{x}) \mathrm{CaxO}$ thin films for blue and ultraviolet optoelectronic applications. Solid State Sciences. 2017;71:42-50.

11. Cullity BD, Stock SR. Elements of X-Ray Diffraction. New York: Prentice-Hall; 2001.

12. Lee JH, Park BO. Characteristics of Al-doped $\mathrm{ZnO}$ thin films obtained by ultrasonic spray pyrolysis: effects of Al doping and an annealing treatment. Materials Science and Engineering: B. 2004;106(3):242-245.

13. Pankove JI. Optical Processes in Semiconductors. Englewood Cliffs: Prentice-Hall; 1971.

14. Burstein E. Anomalous Optical Absorption Limit in InSb. Physical Review. 1954;93(3):632.

15. Sernelius BE, Berggren KF, Jin ZC, Hamberg I, Granqvist CG. Band-gap tailoring of $\mathrm{ZnO}$ by means of heavy $\mathrm{Al}$ doping. Physical Review B. 1988;37(17):10244-10248.

16. Lai HHC, Kuznetsov VL, Egdell RG, Edwards PP. Electronic structure of ternary CdxZn1-xO $(0 \leq \mathrm{x} \leq 0.075)$ alloys. Applied Physics Letters. 2012;100(7):072106.

17. Lu JG, Fujita S, Kawaharamura T, Nishinaka H, Kamada Y, Ohshima T, et al. Carrier concentration dependence of band gap shift in n-type $\mathrm{ZnO}$ :Al films. Journal of Applied Physics. 2007;101(8):083705

18. Kim CE, Moon P, Kim S, Myoung JM, Jang HW, Bang J, et al. Effect of carrier concentration on optical bandgap shift in ZnO:Ga thin films. Thin Solid Films. 2010;518(22):6304-6307.

19. Tsay CY, Fan KS, Lei CM. Synthesis and characterization of sol-gel derived gallium-doped zinc oxide thin films. Journal of Alloys and Compounds. 2012;512(1):216-222.

20. Shinde SS, Shinde PS, Oh YW, Haranath D, Bhosale CH, Rajpure KY. Structural, optoelectronic, luminescence and thermal properties of Ga-doped zinc oxide thin films. Applied Surface Science. 2012;258(24):9969-9976. 
21. Lu HC, Jou JC, Chu CL. Influence of RF magnetron sputtering conditions on the properties of transparent conductive galliumdoped magnesium zinc oxide thin films. Surface and Coatings Technology. 2013;231:539-542.

22. Pei ZL, Sun C, Tan MH, Xiao JQ, Guan DH, Huang RF, et al. Optical and electrical properties of direct-current magnetron sputtered ZnO:Al films. Journal of Applied Physics. 2001;90(7):3432-3436.

23. Shanthi E, Dutta V, Banerjee A, Chopra KL. Journal of Applied Physics. 1982;53(3):1615 - 1621.
24. Minami T, Nanto H, Shooji S, Takata S. The stability of zinc oxide transparent electrodes fabricated by R.F. magnetron sputtering. Thin Solid Films. 1984;111(2):167-174.

25. Fujimura N, Nishihara T, Goto S, Xu J, Ito T. Control of preferred orientation for $\mathrm{ZnOx}$ films: control of self-texture. Journal of Crystal Growth. 1993;130(1-2):269-279.

26. Das AK, Misra P, Ajimsha RS, Bose A, Joshi SC, Phase DM, et al. Studies on temperature dependent semiconductor to metal transitions in $\mathrm{ZnO}$ thin films sparsely doped with Al. Journal of Applied Physics. 2012;112(10):103706. 